\title{
Better or Worse: a Study of Day-to-Day Changes over Five Months of Rosen Method Bodywork Treatment for Chronic Low Back Pain
}

\author{
Alan Fogel, PhD, LMT, Certified Rosen Method Bodywork Teacher and Practitioner \\ Department of Psychology, University of Utah, Salt Lake City, UT, USA
}

Background: Fluctuations of good days and bad days - in physical symptoms and emotional states-are common for individuals with chronic illness. This pilot study examines these fluctuations during bodywork treatment.

Purpose: We analyzed changes in daily selfreports over a period of five months for five individuals who received weekly treatments of Rosen Method Bodywork (RMB), which uses touch and words to enhance body awareness of physical sensations and emotional states.

Subjects and Design: Five subjects (aged 31-56) who had chronic low back pain (CLBP) received 16 weekly treatments given by three experienced RMB practitioners.

Measures: Pre- and posttreatment assessments covered demographics, disability, and pain. Clients also completed daily bedtime assessments of pain, fatigue, emotional state, and sense of control during the entire treatment period.

Results: All clients reported reductions in pain and/or disability in post- compared to pretreatment. In spite of a high level of day-to-day variability in the daily assessments, there were significant reductions in pain and fatigue, and significant increases in positive emotional state and sense of control across the treatment period. In reaching this end, however, some clients had slow and steady improvements, some improved more rapidly, while others got worse before they got better.

Conclusions: The natural course of healingwith its inevitable fluctuations in symptoms - is part of a process leading to successful treatment outcomes. Rosen Method Bodywork may be especially helpful in developing and accepting both sensory and emotional body awareness changes that facilitate overall improvement.

KEY WORDS: Rosen Method Bodywork; chronic low back pain; pain; fatigue; emotion; sense of control

\section{INTRODUCTION}

Fluctuations of good days and bad days are common for individuals with chronic illness. ${ }^{(1,2)}$ While these ups and downs are also likely to occur during treatment, there is relatively little research about this in any health care modality. This study examines day-to-day variability in the perception of physical sensation and emotional state, in a sample of five individuals with chronic low back pain (CLBP) across a period of five months in which they received 16 weekly sessions of Rosen Method Bodywork (RMB).

\section{Chronic Low Back Pain}

It is estimated that $60 \%-80 \%$ of the population will experience CLBP over the life course. As many as $25 \%$ of individuals will not find relief from conventional treatments. ${ }^{(3,4)}$ CLBP has both sensoryphysical and emotional symptoms. In addition to chronic pain and fatigue, individuals with CLBP show higher levels of anger, fear, despair, and lack a sense of control. ${ }^{(5-16)}$

It is generally recognized that CLBP is a dynamic, fluctuating condition with multifactorial etiology and complex pathogenesis. Normally, mechanistic models for CLBP have tended to focus on the mechanicalsensory aspects of musculoskeletal tissues. Psychosocial factors contribute emotional distress in these patients from sources including job dissatisfaction, poor social support, and the influence of pain-related behavior on work and family dynamics. ${ }^{(17-19)}$

Because CLBP individuals are known to suppress their physical pain and also their negative emotions, ${ }^{(6,20-22)}$ body-based treatments for enhancing embodied self-awareness - the ability to feel both body sensations and emotions ${ }^{(23,24)}$ _ may be effective. Yoga, massage, and mindfulness meditation, which can enhance embodied self-awareness, have been shown to reduce pain and disability in CLBP. (4,25-29) Embodied self-awareness practices such as these have also been effective in treating other types of chronic pain conditions to enhance feelings of well-being, reduce fatigue, increase self-control, and reduce disability. ${ }^{(24,30-36)}$

\section{Rosen Method Bodywork}

RMB is a bodywork therapy designed specifically for enhancing embodied self-awareness. ${ }^{(37-43)}$ The 
listening-receptive touch in RMB allows clients to feel sensations and emotions, and promotes a subsequent parasympathetic relaxation response that can be observed in reduced muscle tension, more relaxed breathing, and a sense of ease. ${ }^{(44,45)}$ RMB also uses talking and responsive words to help clients name and become more aware of their sensory and emotional states. RMB has been found to enhance psychological health (increases in positive and decreases in negative emotions), physical health (reduction in pain and muscle tension, improved breathing and digestive function), and awareness of mind-body connection (awareness of how body tension and emotion link to daily life stressors and prior symptoms). ${ }^{(46)} \mathrm{RMB}$ also has been shown to increase oxytocin, reduce stress hormones, and lower perceived pain and pain medication levels. ${ }^{(47,48)}$

RMB is done with the client lying down on a massage table and draped with a sheet and/or blanket. No oils are used in RMB touch. RMB practitioners create a dialogue with clients using their hands and their words to enhance clients' awareness of when they move into and out of embodied self-awareness of their physical sensations and emotional feelings. There is no agenda to "fix" or change anything, only to bring what is observed by the practitioner into the client's present moment awareness. All forms of embodied experience are "allowed", including physical sensations and emotions. ${ }^{(37,38,39)}$ The RMB training process involves a minimum of 252 in-class hours of basic coursework, additional training in professional ethics and anatomy, plus an internship period of 350 client hours including 25 hours of direct supervision, 25 personal bodywork sessions, and six hours of case consultation (http://www.rosensouthwest.com/ certification.html). ${ }^{(42)}$

\section{Research Approach}

As commonly used in investigations of change and development over time-where the process (rather than the outcome) of change is under investigationthis study employs a microgenetic design. ${ }^{(49,50)}$ using frequent observations over an extended period of time in a small number of cases. These designs have the advantage of being immediately applicable to clinical practice by showing the process of change (as in the case of the daily ups and downs in this study) within and across cases, ${ }^{(51,52,53)}$ although because of small sample size, they cannot prove that a method is effective for the population in general.

\section{METHODS}

\section{Research Design}

Clients completed daily assessments of pain, fatigue, emotional state, and sense of control during the approximately five-month treatment period. In addition to the daily assessments, there were pre- and posttreatment questionnaires of pain and disability, a pre- and postinterview about lifestyle and back pain, and a pretreatment inventory of the client's usage of complementary and alternative medical (CAM) practices. The study was approved by the University of Utah IRB and was funded by a grant from the National Institutes of Health (R21 AT002209).

Three certified RMB practitioners were selected because they were all located in the same area of $\mathrm{N}$. California from which the clients were chosen, all had at least ten years of experience as a RMB practitioner, all had previously worked with CLBP, and all were paid by the research grant at their standard rate for giving the sessions. Sessions occurred weekly, or occasionally bi-weekly, depending upon client and practitioner availability.

\section{Hypotheses}

In accord with the existing literature, three hypotheses were advanced:

1) Comparing pre- vs. posttreatment scores on questionnaires and interviews, clients will show a reduction in work disability and pain.

2) There will be wide fluctuations in the daily assessments over time during the treatment period, but clients will show overall reductions in pain and fatigue and increases in positive emotional state and sense of control.

3) There will be interclient differences in progress toward improvement. With increasing embodied self-awareness, it is likely that some clients' selfreported pain or fatigue may increase in the short term, followed by a decrease in later phases of the treatment.

\section{Subjects}

Six clients with CLBP from East San Francisco Bay area of Northern California participated in this study. Clients were recruited with flyers placed in clinics, shops, and cafes. The flyer had the following text: "Female volunteers between the ages of 25-55 who are motivated to overcome chronic back pain may qualify to participate in a research study involving an investigation of Rosen Method Bodywork. The treatment involves 16 sessions over a 4-5 month period. You will be compensated for your participation and all treatment sessions will be free of charge". We wanted only those clients who were motivated to overcome their CLBP so as to better ensure that they would remain in the study for the entire treatment period.

Clients who called were screened by a research assistant who lived in the same area. Clients were selected for the study if they met the following 
criteria: female, a diagnosis by their medical provider of CLBP, working at least part time (four clients were doing office work, one was caring for elderly parents [client 1]), not on disability leave, without other chronic conditions or surgeries in the past year, had not ever received back surgery, not taking psychotropic or other medications except for pain, not pregnant, and not currently receiving medical treatment for back pain. All selected clients were asked to sign an informed consent document that was based on the text of the flyer. Selected clients were between the ages of 31 and 56, had CLBP symptoms between five and 25 years, had at least some postgraduate education, and reported at intake that their back pain had serious effects on their work and personal lives. Three of the clients were formerly massage/bodywork therapists and two were chefs. They all had to change careers because of their CLBP.

Clients had no previous experience with RMB. Based on a checklist of CAM practices created for this study (Alternative medicine: acupuncture, Ayurveda, homeopathy, naturopathy; Biological: chelation, diets [including Adkins, Pritikin, macrobiotic, etc.], vitamins; Manipulative: chiropractic, massage, rolfing, Feldenkrais, craniosacral, other; Mind-body: biofeedback, EMDR, meditation, imagery, progressive relaxation, breathing, hypnosis, yoga, tai chi, Qi gong, prayer, Reiki), the total types of CAM (ever used, used in the past year) were tallied: Client $1(18,9)$, client $2(17,6)$, client $3(24,13)$, client $4(16,9)$, and client $5(8,5)$. In spite of this large number of non-RMB CAM practices used by clients, they still continued to experience debilitating back pain at the onset of their participation in this study.

In exchange for their participation, clients received 16 RMB treatments at no charge and $\$ 150$ at the completion of the study. One client ended her participation in the study after only five sessions, reportedly due to having too many other commitments.

\section{Interviews and Questionnaires}

\section{Pre- and posttreatment questionnaires}

Clients selected for inclusion in the study met in person two weeks before and two weeks after the treatment period with the same research assistant who had done the telephone screening at intake. Three clients were interviewed at home and two at a prereserved meeting room at a Public Library in Berkeley, CA. In the pretreatment interview meetings, occurring between June and October of 2005, clients filled out a questionnaire on CAM use (see above). During both pre- and posttreatment meetings with the RA, clients filled out the Roland-Morris Disability Questionnaire. In this instrument, subjects rate items related to CLBP by thinking of themselves "today", such as, "Because of my back, I try not to bend or kneel down." This assessment has been shown to have excellent internal consistency and is valid in comparison to other measures of physical functioning and work status. ${ }^{(54)}$

Also during these meetings, the same RA did a pre- and posttreatment interview with each client covering demographic information, work experience, and their experience with back pain. Interviews were digitally audio-recorded and later transcribed by different research assistants at the University of Utah.

\section{Pre- and posttreatment interviews}

Three items asked during both the pre- and postinterviews were used in this analysis. Items 1 and 2 were fixed response.

Item 1: On a scale of 0 to 10 , how much pain in your back do you have when it is most intense. Think of 0 as no pain at all and 10 as the worst possible pain.

Item 2 (pre): Overall, since your back pain began, would you say that it has (1) improved, (2) somewhat better, "on again-off again," (3) stayed about the same, or has it (4) worsened?

Item 2 (post): In relation to before you began the Rosen Method, how is your back problem now? Regarding the back pain, would you say is has (1) improved, (2) somewhat better, "on again - off again," (3) stayed about the same, or has it (4) worsened?

Item 3 was open-ended. The responses to this item were transcribed from the digital recordings. A research assistant from the University of Utah, unaware of the hypotheses of the study, used content analysis ${ }^{(55)}$ to break the responses to each item into categorical themes by reading and rereading the transcripts until an exhaustive list was obtained. The categories obtained for this item were as follows:

Item 3 (pre and post): Have you noticed any career/ work changes related to back pain? (1) no change, (2) embodied self-awareness increased, (3) productivity increased, (4) productivity decreased, (5) less pain, (6) increased pain.

After finding the categorical themes using content analysis, the same research assistant coded all the categories that were mentioned by a client for each item. A second research assistant, also unaware of the hypotheses and using the same categories from the content analysis, independently recoded the transcriptions. Reliability between the two coders was high, kappa $=.85$ and percent agreement $=.94$.

\section{Daily questionnaires}

Finally, clients were given a packet of blank forms for four daily assessments - regarding pain, fatigue, emotional state, and sense of control-over the course of treatment. They were instructed to complete all four assessments every night at bedtime during the treatment period and to return the completed packet to the RA at the final meeting. Several clients began to fill out their questionnaires a few days before treatment began, and others filled them out for a few days after treatment, but there were an 
insufficient number of pre- and posttreatment daily assessments to compare them statistically. We relied on the pre- and postquestionnaires and interview, described in the previous section, for this pre-post comparison. The daily data collection during treatment resulted in an approximately 5.5 month period, an average of 165 days of data per client (Total $\mathrm{N}=$ 850 , range per client $=153-196$ ) across the treatment period. The following instruments were used for the daily assessments.

Pain (daily). Using the Margolis pain rating method, on a scale from 0 to 100 , clients rated the "percent of the waking day in which you had pain". (56) These daily pain ratings are valid in comparison to recalled pain assessed weekly using standardized pain assessments. ${ }^{(57)}$

Fatigue (daily). On a scale from 0 to 100 , clients rated the "percent of the waking day in which you had fatigue". This scale has good reliability and validity when used in conjunction with the daily Margolis pain ratings and daily emotional state assessments using the POMS. ${ }^{(58)}$

Emotional state (daily). Clients used the Profile of Mood States (POMS), ${ }^{(59)}$ with 40-items such as "I feel rather distressed", and "Overall, I am satisfied". Clients rate how each item describes their current feeling on a scale from $1=$ "not at all" to $4=$ "very well". The POMS has good internal consistency with a highly stable factor structure. ${ }^{(60)}$ For this study, a single factor (positive vs. negative states) emerged as salient. Scores reported represent the client's daily score on that factor, normalized to a percentage of the maximum score. Higher factor scores represent more positive emotional states.

Sense of control (daily). Clients used the Pearlin and Schooler Mastery Scale, ${ }^{(61)}$ with six items such as "I often felt helpless today in dealing with the problems of life". Clients rate how each item describes their feeling today on a scale from $1=$ "strongly agree" to $4=$ "strongly disagree". The PSMS has good internal consistency and is correlated with somatic health measures. ${ }^{(62,63)}$ For this study, a single factor (more vs. less control) emerged as salient. Scores reported represent the client's daily score on that factor, normalized to a percentage of the maximum score. Lower factor scores represent more sense of control.

\section{Data Analysis}

There were too few clients to perform statistics on the pre- and posttreatment items. Instead, a binomial sign test was performed across all items and subjects. This test calculates the observed percentage of items that were in the predicted direction (e.g., post-test lower on pain and disability than pretest), and compares this to the expected percentage of items in the predicted direction, which would be $50 \%$. To be significant, the binomial sign test must detect that the percentage of items in the predicted direction is significantly higher than expected by chance.

Change over days across the treatment period within clients for each of the four daily assessments was modeled using a regression curve-fitting procedure for each measure and each client. The independent variable is day and the dependent variables are percent of the day in pain, percent of the day fatigued, percent factor score on emotional state (higher scores indicate a more positive emotional state), and percent factor score on sense of control (lower scores indicate a higher sense of control). To account for both linear and nonlinear effects, ${ }^{64,65)}$ the regression model was:

Percent variable $=\beta_{0}$ (intercept) $+\beta_{1} \times$ day (linear change) $+\beta_{2} \times$ day $^{2}$ (quadratic change)

Significance of the overall model was checked using an F-test. Additional terms may be added to such models (cubic, exponential); however, linear and quadratic terms are sufficient to capture the shape of most real-world change trajectories. ${ }^{(66)}$

Over the course of the four-month daily data collection period, the number of missing observations compared to the total days during the treatment period was 15/173 (Client 1), 9/196 (Client 2), 0/168 (Client 3), 6/153 (Client 4), and 19/160 (Client 5), for a total of $5.7 \%$ of missed days. The regression analysis was run twice, the first time ignoring missing values and the second time using a linear interpolation procedure in which the missing days were given values equal to the average of the preceding and following days in which data were available. There was no difference in the significance levels of the findings and only minor differences in the regression parameters. Results are reported for the analysis that included linear interpolation. Finally, we examined correlations across days between each of the daily assessments to look for coordinated changes.

\section{Fidelity of Rosen Method Sessions}

The RMB practitioners who participated in this study were briefed by email and telephone contacts and one in-person meeting with the author, also a RMB practitioner. Practitioners made direct arrangements for sessions with the client-participants to whom they had been randomly assigned. Practitioners knew that the sample consisted of CLBP females and were instructed to simply provide RMB sessions in their own offices as they normally would for any client. Sessions were digitally audio-recorded by the practitioners. These recordings were used as a fidelity check. The author listened to the recordings for all clients in the study as they were received from practitioners within two weeks of the session. In the author's judgment, there were no departures from standard RMB practice. Because of their extensive 
experience as RMB practitioners, no further supervision was deemed necessary.

\section{RESULTS}

\section{Pre- and Posttreatment Questionnaires and Interviews}

Table 1 lists the scores for each client on each measure. All clients changed for the better on each of the items. The Roland-Morris Disability Questionnaire showed that all clients felt less disabled (had lower scores) following the RMB treatments compared to before. For Item 1, when considering their most intense pain, all clients reported reductions in the post- compared to pretreatment period.

For Item 2 which asks whether their back pain has improved or worsened since their symptoms began (pretreatment) and since the start of their RMB treatments until the end of those treatments (posttreatment), Clients $1-4$ said their pain showed noticeable improvement after the RMB treatments, compared to no or only gradual improvement before treatment. Client 5 said that her pain had not changed, but it had not gotten progressively worse as it had been doing before the RMB treatments, which was counted as an improvement. For Item 3, all clients described improvements at work; most mentioned reductions of pain and increased productivity at work. Although we did not specifically ask about body awareness, some clients spontaneously mentioned that their embodied self-awareness during work had increased. Note that Item 3 was open-ended, so we do not have an exact comparison on the same content themes from pre- to posttreatment.

It was decided, therefore, that all 20 items in Table 1 revealed reductions in pain and disability after, compared to before, treatment. Using the binomial sign test, the probability of obtaining $20 / 20$ items in the predicted direction is extremely small $(p<.001)$.
Even if Client 5's response to Item 2 is counted as a nonimprovement, $19 / 20$ items is still highly unlikely $(p<.001)$.

\section{Change over Time in Daily Assessments during the Treatment Period}

\section{Day-to-day variability}

The means and standard deviations of the daily assessments are shown in Table 2. There was an extremely high day-to-day variability in both pain and fatigue. The variability in emotional state and sense of control was also high, but tended to be lower than that for pain and fatigue. To illustrate the degree of variability, Figure 1 shows the daily data from Client 3 for emotional state and sense of control. Although there is a great deal of change between days, there is also a generally upward trend toward more positive emotions and a greater sense of control.

\section{Trends across treatment}

The statistical tests for trends across treatment for all measures and subjects - including the regression coefficients for the intercept, linear, and quadratic terms of the model - are shown in Table 3. As expected, there were overall significant reductions in pain and fatigue, and significant increases in positive emotional state and sense of control. Figures 2-5 show the modeled trajectories for each measure and each client. Note that in Figure 2, one of the modeled trajectories for pain has a negative value, which is an artifact of the regression prediction algorithm. There were no actual data points with a value less than zero. Emotional state and sense of control show primarily linear and steadily improving trajectories for most subjects. Pain and fatigue, however, in addition to high levels of day-to-day variability (Table 1), also have more variable and nonlinear trends. Some subjects got worse before they got better (inverted U-shaped modeled trajectories).

TABLE 1. Responses on Pre- and Posttreatment Interview and Questionnaire Measures

\begin{tabular}{|c|c|c|c|c|c|}
\hline Client & $\begin{array}{c}\text { Pre } \\
\text { vs. Post }\end{array}$ & $\begin{array}{l}\text { Roland- } \\
\text { Morris }\end{array}$ & $\begin{array}{c}\text { Item 1: } \\
\text { Most intense pain (1-10) }\end{array}$ & $\begin{array}{c}\text { Item } 2: \\
\text { Pain better or worse? }\end{array}$ & $\begin{array}{c}\text { Item 3: } \\
\text { Effect of pain on work }\end{array}$ \\
\hline \multirow[t]{2}{*}{1} & Pre & 5 & 7.5 & Somewhat better & Productivity decreased, pain increased \\
\hline & Post & 2 & 5 & Improvement & More embodied self-awareness \\
\hline \multirow[t]{2}{*}{2} & Pre & 6 & 9 & Somewhat better & Productivity decreased, pain increased \\
\hline & Post & 5 & 5 & Improvement & More embodied self-awareness \\
\hline \multirow[t]{2}{*}{3} & Pre & 8 & 9.5 & Worse & Pain increased \\
\hline & Post & 3 & 7.5 & Improvement & More embodied self-awareness \\
\hline \multirow[t]{2}{*}{4} & Pre & 17 & 10 & Somewhat better & Productivity decreased \\
\hline & Post & 0 & 9 & Improvement & Productivity increased \\
\hline \multirow[t]{2}{*}{5} & Pre & 5 & 9 & Worse & Productivity decreased, pain increased \\
\hline & Post & 4 & 8 & No change & Pain decreased \\
\hline
\end{tabular}


TABle 2. Means and Standard Deviations of Daily Assessments of Pain, Fatigue, Emotional State, and Sense of Control for Each Client During the Treatment Period

\begin{tabular}{lccc}
\hline \multicolumn{1}{c}{ Measure } & Client & Mean & Standard Deviation \\
\hline Percent of Day in Pain & 1 & 4.34 & 4.63 \\
& 2 & 15.44 & 5.31 \\
& 3 & 3.20 & 3.77 \\
Percent of Day Fatigued & 4 & 16.88 & 13.58 \\
& 5 & 14.86 & 7.57 \\
& 1 & 20.14 & 12.67 \\
& 2 & 19.30 & 9.59 \\
Percent Factor Score & 3 & 9.97 & 6.93 \\
Emotional State & 4 & 40.59 & 48.72 \\
& 5 & 35.95 & 14.58 \\
& 1 & 47.75 & 13.38 \\
Percent Factor Score Sense & 1 & 49.31 & 13.93 \\
of Control & 3 & 51.77 & 11.33 \\
& 4 & 47.58 & 12.90 \\
& 5 & 49.41 & 12.46 \\
& 3 & 46.67 & 9.52 \\
& 45.75 & 9.32 \\
& 4 & 46.95 & 9.81 \\
& 5 & 45.19 & 8.18 \\
& & & 11.08 \\
\hline
\end{tabular}

Some got better then worsened again toward the end of treatment (U-shaped modeled trajectories), although they ended treatment with less pain and fatigue than at the start.

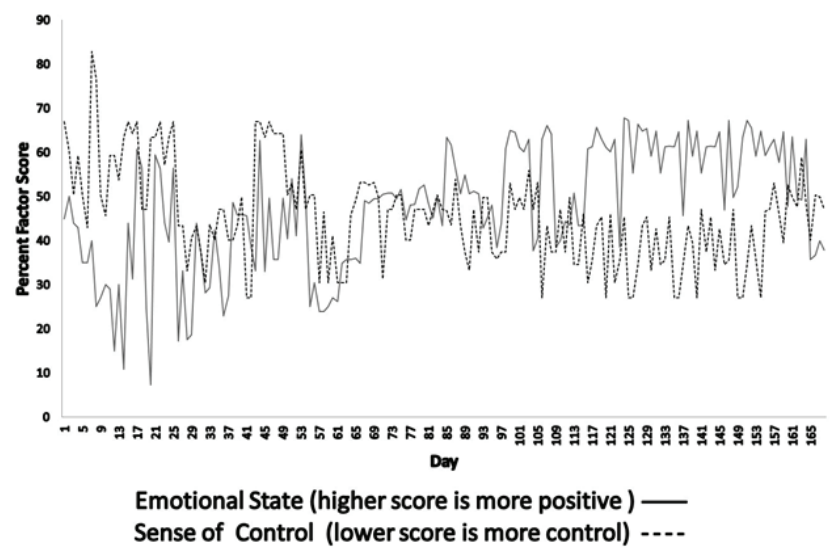

FIGURE 1. Day-to-day variability in emotional state and sense of control for Client 3 across the treatment period. In spite of high levels of daily variability, there is a general linear trajectory of improvement for both measures, as confirmed by the regression models for Client 3, shown in Figures 4 and 5.

Table 4 shows that the correlations between these variables across days mirrored the results of the change trajectories individually. Decreased pain was significantly associated with decreased fatigue, increased positive emotional state, and increased sense of control. Additionally, decreased fatigue is related to more positive emotional state and sense of control, and positive emotional state also correlates with more sense of control.

TABle 3. Intercept, Linear, and Quadratic Regression Parameters for the Curve-Fit Model of Changes Over Days in Pain, Fatigue, Emotional State, and Sense of Control During the Treatment Period for Each Client

\begin{tabular}{|c|c|c|c|c|c|}
\hline Measure & Client & $\begin{array}{c}\text { Intercept } \\
\beta_{0}\end{array}$ & $\begin{array}{c}\text { Linear } \\
\beta_{1}\end{array}$ & $\begin{array}{c}\text { Quadratic } \\
\beta_{2}\end{array}$ & $F$-test ${ }^{a}$ \\
\hline \multirow[t]{5}{*}{ Percent of Day in Pain } & 1 & 3.34 & .034 & .000 & $00.63[\mathrm{df}=2,144]$ \\
\hline & 2 & 5.53 & .272 & -.001 & $29.53[\mathrm{df}=2,148] * * *$ \\
\hline & 3 & 15.89 & -.263 & .001 & $15.19[\mathrm{df}=2,122] * * *$ \\
\hline & 4 & 1.76 & .657 & -.005 & $39.68[\mathrm{df}=2,122] * * *$ \\
\hline & 5 & 29.44 & -.381 & .002 & $64.84[\mathrm{df}=2,150] * * *$ \\
\hline \multirow[t]{5}{*}{ Percent of Day Fatigued } & 1 & 29.77 & -.214 & .001 & $2.98 *$ \\
\hline & 2 & 34.09 & -.129 & .000 & $42.54 * * *$ \\
\hline & 3 & 27.42 & -.380 & .002 & $7.08 * *$ \\
\hline & 4 & 30.21 & .713 & -.005 & $16.71 * * *$ \\
\hline & 5 & 55.23 & -.691 & .004 & $29.77 * * *$ \\
\hline \multirow[t]{5}{*}{ Percent Factor Score Emotional State } & 1 & 34.71 & .26 & -.01 & $6.29 * *$ \\
\hline & 2 & 14.81 & .590 & -.002 & $20.83 * * *$ \\
\hline & 3 & 25.21 & .343 & .000 & $43.05 * * *$ \\
\hline & 4 & 34.24 & .214 & .000 & $8.75 * * *$ \\
\hline & 5 & 36.71 & .398 & -.002 & $12.73 * * *$ \\
\hline \multirow[t]{5}{*}{ Percent Factor Score Sense of Control } & 1 & 40.89 & .181 & -.001 & 2.87 \\
\hline & 2 & 59.59 & -.244 & .001 & $4.91 *$ \\
\hline & 3 & 62.34 & -.317 & .001 & $11.75 * * *$ \\
\hline & 4 & 49.65 & .061 & .000 & $18.55 * * *$ \\
\hline & 5 & 62.38 & -.634 & .004 & $53.57 * * *$ \\
\hline
\end{tabular}

a Significance levels are: $* p<.05, * * p<.01, * * * p<.001$. 


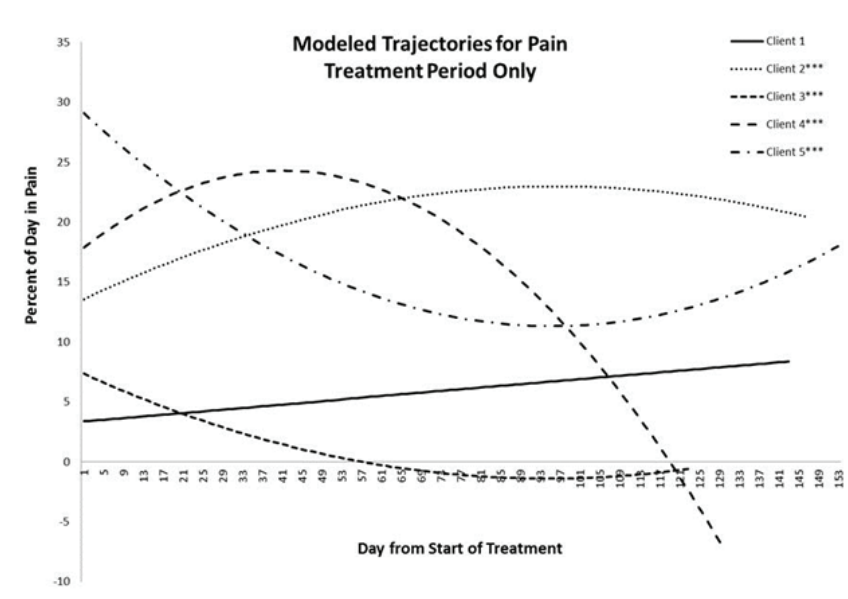

FIGURE 2. Regression models of pain for each client during the treatment period. Significance of the regression $F$-values for each client are as follows (see also, Table 3 ): $* * * p<.001$.

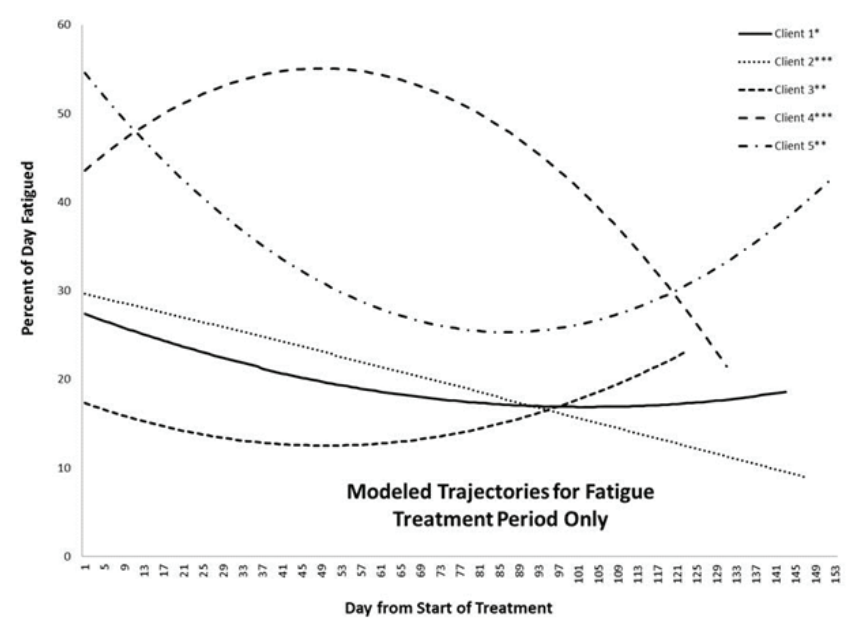

FIGURE 3. Regression models of fatigue for each client during the treatment period. Significance of the regression F-values for each client are as follows (see also, Table 3): *p $<.05,{ }^{* *} p<.01$, ***p $<.001$.

TABle 4. Correlations Between Pain, Fatigue, Emotional State, and Sense of Control Across Treatment Days for all Clients Combined; Correlations Were also Run on Each Client Individually and Show the Same Pattern of Results

\begin{tabular}{lccc}
\hline & $\begin{array}{c}\text { Percent of } \\
\text { Day in Pain }\end{array}$ & $\begin{array}{c}\text { Percent of } \\
\text { Day Fatigued }\end{array}$ & $\begin{array}{c}\text { Percent } \\
\text { Factor Score } \\
\text { Emotional State }\end{array}$ \\
\hline Percent of Day & $+.56^{\mathrm{a}}$ & & \\
Fatigued & $\mathrm{N}=655$ & & \\
$\begin{array}{l}\text { Percent Factor Score } \\
\text { Emotional State }\end{array}$ & $-.12^{\mathrm{b}}$ & $-.25^{\mathrm{a}}$ & \\
$\begin{array}{l}\text { Percent Factor Score } \\
\text { Sense of Control }\end{array}$ & $\mathrm{N}=642$ & $\mathrm{~N}=682$ & \\
& & $+.22^{\mathrm{a}}$ & $-.38^{\mathrm{a}}$ \\
\hline
\end{tabular}

aSignificance level: $p<.001$.

bSignificance level: $p<.01$

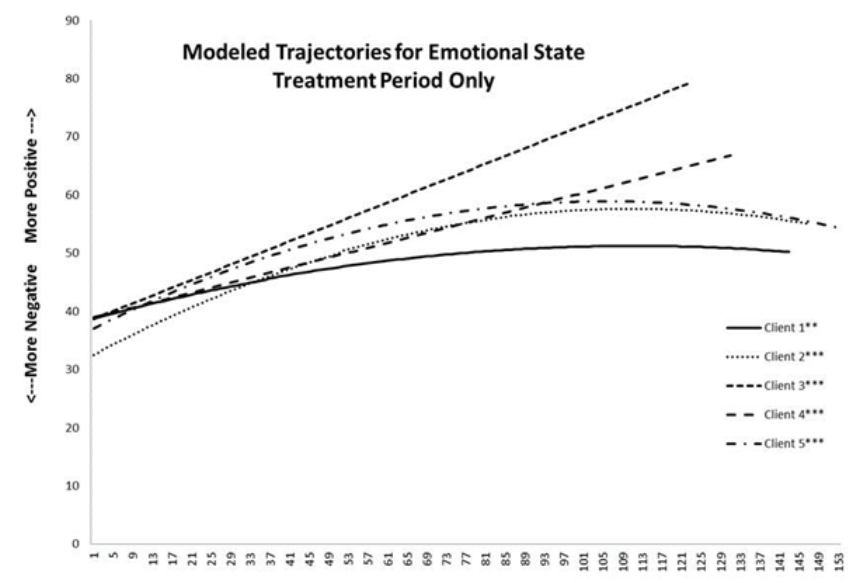

Day from Start of Treatment

FIGURE 4. Regression models of emotional state for each client during the treatment period. Significance of the regression $F$-values for each client are as follows (see also, Table 3): $* * p<.01, * * * p<.001$.

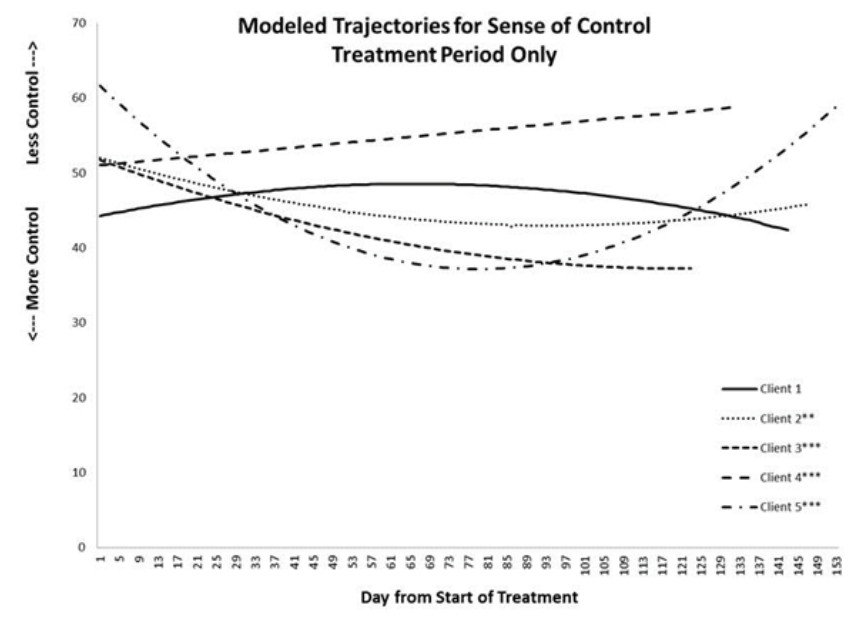

FIGURE 5. Regression models of sense of control for each client during the treatment period. Note that lower scores mean higher sense of control. Significance of the regression F-values for each client are as follows (see also, Table 3): $* * p<.01$, ***p $<.001$.

\section{DISCUSSION \& CONCLUSION}

Comparing pre- vs. posttreatment measures (Hypothesis 1), when considering their most intense pain, all clients reported reductions. All felt less disabled and reported a more satisfactory work experience. In terms of the shape of the growth curves (Hypotheses 2 and 3 ), in spite of large day-to-day fluctuations, there were significant reductions in pain and fatigue, and significant increases in positive emotional state and sense of control. Some clients first increased in their pain and fatigue followed by a decline, while others showed either an abrupt drop that leveled off or increased slightly at the end, or else there was a steady decline. One client did not show significant changes in pain over time. Emotional state tended to increase linearly for most clients. Sense of control increased 
linearly for three clients, did not change for one, and decreased for another. Even though they were not directly asked, some clients spontaneously mentioned the importance to them of learning to better pay attention to their body's feelings as a result of RMB.

\section{Case Summaries}

Client 1. This client reported relatively low levels of back pain (an average of $4 \%$ of the day in pain) on the daily assessments, without significant change across the RMB treatment period. She also had no significant change in sense of control. Like other clients, however, her fatigue decreased and her positive emotional state increased over time during treatment. In her posttreatment interview, however, in spite of the nonsignificant findings on daily pain scores, she reported less pain compared to pretreatment, a reduction from $7.5 / 10$ to $5 / 10$ on the most intense pain, reduced work disability, and more self-awareness at work. It may be that she became aware of the change in her "background" level of pain only after the treatments were completed.

Client 2. Client 2 reported an average of $15 \%$ of the day in pain. While she had steady reductions in fatigue and steady increases in positive emotional state and sense of control, her pain increased during the middle treatment period before decreasing to lower levels than at the outset of treatment. In her posttreatment interview she reported less pain compared to pretreatment, a reduction from $9 / 10$ to $5 / 10$ on the most intense pain, reduced work disability, and more embodied self-awareness at work.

Client 3. This client reported a relatively low average of $3 \%$ of the day in pain overall, and a significant reduction in that pain over the course of treatment. While she had steady increases in positive emotional state and sense of control, her fatigue actually increased over time. Her overall fatigue, however, is considerably lower than the other four clients $(10 \%$ of the day), and even at the highest level of fatigue at the end of treatment for this client, it was at similar end-levels reported by other clients who showed reductions in fatigue over time (about $20 \%$ of the day). In her posttreatment interview she reported less pain compared to pretreatment, a reduction from 9.5/10 to $7.5 / 10$ on the most intense pain, reduced work disability, and more embodied self-awareness at work.

Client 4. This client reported the highest amount of daily pain, $17 \%$ of the day in pain on average. Like Client 2, her pain increased during the first one-third of treatment and then declined. Fatigue had a similar trajectory. She had steady increases in positive emotional state, but reductions over time in her sense of control. In her posttreatment interview she reported somewhat less pain compared to pretreatment, a reduction from 10/10 to only $9 / 10$ on the most intense pain, but she had the largest reduction in work disability of any client, and she reported more productivity at work.

Client 5. Client 5 reported an average of $15 \%$ of the day in pain overall. Pain and fatigue had similar trajectories, quadratically declining for the first half of the treatment period and then leveling off. There was a steady increase in positive emotional state and a quadratic increase in sense of control. In her posttreatment interview she reported somewhat less pain compared to pretreatment, a reduction from $9 / 10$ to only $8 / 10$ on the most intense pain, and also mentioned that her pain had not really improved but at least had not continued to worsen. There was, however, reduced work disability and she mentioned that she had less pain at work.

\section{Limitations}

This pilot study is meant to measure process rather than an outcome. The design cannot tell whether RMB is better than another treatment or better than no treatment because this was a small sample and there was no control group. We also cannot distinguish the effects of RMB per se, nor the more general effects of the client-practitioner relationship. Although the one subject who ended her participation mentioned other commitments, we don't know if the treatment affected her adversely.

Nevertheless, improvements were shown for all clients both on the pre- vs. postmeasures, as well as the daily assessments, suggesting that more research on RMB for CLBP is warranted. Future research on a similar female population may also benefit by including assessments in changes of physical exercise, changes in the use of pain medication, ${ }^{(48)}$ use of other CAM practices, and menopausal/hormonal function. Finally, some of the pre- and postinterview questions were made especially for this study and may not generalize to other studies and samples.

\section{Clinical Implications}

While this research is limited from the perspective of the more standard randomized control trial (RCT) design, case-based approaches in which clients are observed at frequent intervals over the course of treatment provide clinically valuable information that RCT studies cannot provide. The advantages of these microgenetic case study designs include: (1) helping to decide how particular treatments affect particular individuals, (2) understanding the role of symptom variability over time, and (3) getting a more evidencebased sense of the complexity and time course of treatment approaches. ${ }^{(50)}$

Even though a treatment may be effective overallas it was for these five individuals - ups and downs 
appear to be a normal part of the clinical change process and each person responds to the treatment in a different way. Research shows that bodywork treatment protocols are inherently complex and change over time, and effective bodywork practice involves adapting the treatment protocol to the needs of the patient in any particular moment. ${ }^{(67)}$ The time course across different types of treatment for both physical and mental illness and pain shows similar patterns of change in physical and emotional symptoms as found here: stable, gradual or rapid improvement, and fluctuating periods of improvement and worsening. ${ }^{68-71)}$

From a clinical perspective, the generally increasing positive emotions and a growing regulatory sense of control found in these clients may have allowed them to remain committed to the treatment even in the face of temporary setbacks of their pain and fatigue symptoms. During the course of illness recovery, increases in a positive emotion, such as acceptance, can contribute significantly toward overall improvement even in the face of temporary worsening of physical symptoms. ${ }^{(72)}$

Further research with larger samples and appropriately designed control groups will be needed to see if RMB is an effective treatment for chronic pain conditions, especially CLBP. In addition, further research is needed-both for RMB and other bodywork practices-on the clinical implications of interindividual variability and the nonlinear trajectories of both sensory and emotional changes in response to treatment.

\section{CONFLICT OF INTEREST NOTIFICATION}

The author declares there are no conflicts of interest.

\section{COPYRIGHT}

Published under the CreativeCommons AttributionNonCommercial-NoDerivs 3.0 License.

\section{REFERENCES}

1. Charmaz K. Good Days Bad Days: The Self in Chronic Illness and Time. New Brunswick, NJ: Rutgers University Press; 1997.

2. Whitehead L. Toward a trajectory of identity reconstruction in chronic fatigue syndrome/myalgic encephalomyelitis: a longitudinal qualitative study. Int J Nurs Stud. 2006;43:1023-1031.

3. Frank JW, Kerr MS, Brooker AS, DeMaio SE, Maetzel A, Shannon HS, et al. Disability resulting from occupational low back pain: Part 1: What do we know about primary prevention? A review of scientific evidence on prevention before disability begins. Spine. 1996;21(24):2908-2917.

4. Quinn F, Hughes C, Baxter GD. Complementary and alternative medicine in the treatment of low back pain: a systematic review. Phys Ther Rev. 2006;11(2):107-116.
5. Brage S, Sandanger I, Nygård JF. Emotional distress as a predictor for low back disability: a prospective 12-year populationbased study. Spine. 2007;32(2):269-274.

6. Burns JW. Arousal of negative emotions and symptomspecific reactivity in chronic low back pain patients. Emotion. 2006;6(2):309-319.

7. Currie SR, Wang J. Chronic back pain and major depression in the general Canadian population. Pain. 2004;107(1-2):54-60.

8. Fishbain DA, Cutler RB, Cole B, Lewis J, Smets E, Rosorneff HL, et al. Are patients with chronic low back pain and chronic neck pain fatigued? Pain Med. 2004;5(2);187-195.

9. Friedrich M, Hahne J, Wepner F. A controlled examination of medical and psychosocial factors associated with low back pain in combination with widespread musculoskeletal pain. Phys Ther. 2009;89(8):786-803.

10. Flor H, Turk DC, Birbaumer N. Assessment of stress-related psychophysiological reactions in chronic back pain patients. $J$ Consult Clin Psychol. 1985;53(3):354-364.

11. Gatchel RJ, Bernstein D, Stowell AW, Pransky G. Psychosocial differences between high-risk acute vs. chronic low back pain patients. Pain Pract. 2008;8(2):91-97.

12. Hagen EM, Svensen E, Eriksen HR, Ihlebaek CM, Ursin H. Comorbid subjective health complaints in low back pain. Spine. 2006;31(13):1491-1495.

13. Keefe FJ, Rumble ME, Scipio CD, Giordano LA, Perri LM. Psychological aspects of persistent pain: current state of the science. J Pain. 2004;5(4):195-211.

14. Mitchell T, O'Sullivan PB, Smith A, Barnett AF, Straker L, Thornton J, et al. Biopsychosocial factors are associated with low back pain in female nursing students: a cross-sectional study. Int J Nurs Stud. 2009;46(5):678-688.

15. Turk DC, Burwinkle TM. Assessment of chronic pain in rehabilitation: outcomes measures in clinical trials and clinical practice. Rehabil Psychol. 2005;50(1):56-64.

16. Turk DC, Okifuji A. Psychological factors in chronic pain: evolution and revolution. J Consult Clin Psychol. 2002;70(3):678-690.

17. Preuper HRS, Boonstra AM, Wever D, Heuts P, Dekker J, Smeets RJ, et al. Differences in the relationship between psychosocial distress and self-reported disability in patients with chronic low back pain in six pain rehabilitation centers in the Netherlands. Spine. 2011;36(12):969-976.

18. Kovacs F, Abraira V, Zamora J, Teresa Gil del Real M, Llobera J, Fernández C, et al. Correlation between pain, disability, and quality of life in patients with common low back pain. Spine. 2004;29(2)206-210.

19. Guzman J, Esmail R, Karjalaimen K, Malmivaara A, Irvin E, Bombardier C. Multidisciplinary rehabilitation for chronic low back pain: systematic review. BMJ. 2001;322(7301):1511-1516.

20. Bru E, Mykletun RJ, Svebak S. Neuroticism, extraversion, anxiety and Type A behaviour as mediators of neck, shoulder and lower back pain in female hospital staff. Pers Indiv Differ. 1993;15(5):485-492.

21. Carson JW, Keefe FJ, Lowry KP, Porter LS, Goll V, Fras AM. Conflict about expressing emotions and chronic low back pain: associations with pain and anger. J Pain. 2007;8(5):405-411.

22. Zautra A, Smith B, Affleck G, Tennen H. Examinations of chronic pain and affect relationships: applications of a dynamic model of affect. J Consult Clin Psychol. 2001;69(5):786-795. 
23. Fogel A. The Psychophysiology of Self-Awareness: Rediscovering the Lost Art of Body Sense. NY: W. W. Norton; 2009:416.

24. Craig AD. Interoception and emotion: a neuroanatomical perspective. In: Lewis M, Haviland-Jones JM, Barrett LF, eds. Handbook of Emotions, 3rd edition. New York, NY: The Guilford Press; 2008:272-288.

25. Tekur P, Singphow C, Nagendra HR, Raghuram N. Effect of short-term intensive yoga program on pain, functional disability, and spinal flexibility in chronic low back pain: a randomized control study. J Altern Complem Med. 2008;14(6):637-644.

26. Groessl EJ, Weingart KR, Aschbacher K, Pada L, Baxi S. Yoga for veterans with chronic low-back pain. J Altern Complem Med. 2008;14(9):1123-1129.

27. Morone NE, Greco CM, Weiner, DK. Mindfulness meditation for the treatment of chronic low back pain in older adults: a randomized controlled pilot study. Pain. 2008;134(3):310-319.

28. Furlan AD, Imamura M, Dryden T, Irwin E. Massage for low back pain: an updated systematic review within the framework of the Cochrane Back Review Group. Spine. 2009;34(16):1669-1684.

29. Hsu C, BlueSpruce J, Sherman K, Cherkin D. Unanticipated benefits of CAM therapies for back pain: an exploration of patient experiences. J Altern Complem Med. 2010;16(2):157-163.

30. Anderson B, Strand LI, Råheim M. The effect of long-term body awareness training succeeding a multimodal cognitive behavior program for patients with widespread pain. J Musculoskelet Pain. 2007;15(3):19-29.

31. Bakal D. Minding the Body: Clinical Uses of Somatic Awareness. New York, NY: Guilford Press; 1999:228.

32. Fogel A. The brain and bodywork: exploring pain through body sense. Massage and Bodywork. 2011;March/April:54-61.

33. Lee MS, Pittler MH, Ernst E. Internal Qigong for pain conditions: a systematic review. J Pain. 2009;10(11):1121-1127.

34. Salmon P, Lush E, Jablonski M, Sephton SE. Yoga and mindfulness: clinical aspects of an ancient mind/body practice. Cogn Behav Pract. 2009;16(1):59-72.

35. Teixeira ME. Meditation as an intervention for chronic pain: an integrative review. Holist Nurs Pract. 2008;22(4):225-234.

36. Zeigler G, Dahnke R, Yeragani VK, Bar K. The relation of ventromedial prefrontal cortex activity and heart rate fluctuations at rest. Eur J Neurosci. 2009;30(11):2205-2210.

37. Berger D. Rosen method bodywork. In: Davis CM, ed. Complementary Therapies in Rehabilitation: Holistic Approaches for Prevention and Wellness. Thorofare, NJ: SLACK Incorporated; 1997:49-65.

38. Fogel A. Rosen method bodywork: practice and science. Somatics. 2011;16(4):4-8.

39. Mayland EL. Rosen Method: An Approach to Wholeness and Well-Being Through the Body. Santa Cruz, CA: 52 Stone Press; 2005.

40. Rosen M, Benner S. Rosen Method Bodywork: Accessing the Unconscious Through Touch. Berkeley, CA: North Atlantic Books; 2003:152.

41. Wooten S. Rosen method bodywork. Intl J Altern Complem Med. 1994;12(8):9-13.

42. Wright MK. Progress report on the global reorganization of the Rosen Institute: policy, leadership, conflict resolution, and continuing education. Rosen Method Int J. 2010;3(1):3-11. Available from: (http://rosenjournal.org/journal/4/2.pdf).
43. Wright MK. Bringing the inside out. Somatics: the MagazineJournal of the Mind-Body Arts and Sciences. 2011;16(3);4-7.

44. Kerr CE, Wasserman RH, Moore, CI. Cortical dynamics as a therapeutic mechanism for touch healing. J Altern Complem Med. 2007;13(1):59-66.

45. Mangan GL, Murphy G, Farmer RG. The role of muscle tension in "repression". Pavlov J Biol Sci. 1980;15(4):172-176.

46. Hoffren-Larsson R, Gustafsson B, Falkenberg T. Rosen Method Bodywork: an exploratory study of an uncharted complementary therapy. J Altern Complem Med. 2009;15(9):1-6.

47. Holt-Lunstad J, Birmingham WA, Light KC. The influence of a "warm touch" support enhancement intervention among married couples on ambulatory blood pressure, oxytocin, alpha amylase, and cortisol. Psychosom Med. 2008;70(9):076-985.

48. da Silva T. Reducing extreme pain. Rosen Method Int J. 2009;2(1):11-18.

49. Flynn E, Siegler R. Measuring change: current trends and future directions in microgenetic research. Infant Child Dev. 2007;16(1):135-149.

50. Lavelli M, Pantoja APF, Hsu HC, Messinger D, Fogel A. Using microgenetic designs to study change processes. In: Teti DG, ed. Handbook of Research Methods in Developmental Science. Cambridge: Blackwell Publishers; 2004:40-65.

51. Borckardt JJ, Nash MR, Murphy MD, Nixon M, Shaw D, O'Neil P. Clinical practice as natural laboratory for psychotherapy research. Am Psychol. 2008;63(2):77-95.

52. Fogel A. Dynamic systems research on interindividual communication: the transformation of meaning-making. $J \mathrm{Dev}$ Processes. 2006;1(1):7-30.

53. Fogel A, Garvey A, Hsu H, West-Stroming D. Change Processes in Relationships: A Relational - Historical Research Approach. Cambridge, UK: Cambridge University Press; 2006:304.

54. Turner JA, Fulton-Kehoe D, Franklin G, Wickizer TM, Wu R. Comparison of the Roland-Morris Disability Questionnaire and generic health status measures: a population-based study of workers' compensation back injury claimants. Spine. 2003;28(10):1061-1067.

55. Krippendorf KH. Content Analysis: An Introduction to Its Methodology, second edition. Thousand Oaks, CA: Sage; 2004.

56. Margolis RB, Chibnall JT, Tait RC. Test-retest reliability of the pain drawing instrument. Pain. 1988;33(1):49-51.

57. Jamison RN, Raymond SA, Slawsby EA, McHugo GJ, Baird JC. Pain assessment in patients with low back pain: Comparison of weekly recall and momentary electronic data. J Pain. 2006;7(3):192-199.

58. Black CD, O'Connor PJ, McCully KK. Increased daily physical activity and fatigue symptoms in chronic fatigue syndrome. Dyn Med. 2005;4(3):1-9.

59. Lorr M, McNair DM, Heuchert JWP, Droppleman LF. Profile of Mood States (POMS). North Tonawanda, NY: MHS; 1971.

60. Norcross JC, Guadagnoli E, Prochaska JO. Factor structure of the Profile of Mood States (POMS): Two partial replications. J Clin Psychol. 1984;40(5):1270-1277.

61. Pearlin LI, Schooler C. The structure of coping. J Health Soc Behav. 1978;19:2-21.

62. Folkman S, Lazarus RS, Gruen RJ, DeLongis A. Appraisal, coping, health status, and psychological symptoms. JPers Soc Psychol. 1986;50(1):571-579. 
63. Lachman ME, Weaver SL. The sense of control as a moderator of social class differences in health and well-being. J Pers Soc Psychol. 1998;74(3):763-773.

64. Cheshire A, Muldoon KP, Francis B, Lewis CN, Ball LJ. Modelling change: new opportunities in the analysis of microgenetic data. Infant Child Dev. 2007;16(1):119-134.

65. Grimm KJ, Ram N, Hamagami F. Nonlinear growth curves in developmental research. Child Dev. 2011;82(5):1357-1371.

66. Aiken LS, West SG. Multiple Regression: Testing and Interpreting Interactions. Thousand Oaks, CA: Sage; 1991.

67. Porcino AJ, Boon HS, Page SA, Verhoef MJ. Exploring the nature of therapeutic massage bodywork practice. Intl J of Ther Massage Bodywork. 2013;6(1):15-24.

68. Glasziou P, Chalmers I, Rawlins M, McCulloch R. When are randomized trials unnecessary? Picking signal from noise. $B M J$. 2007;334(7589):349-351.

69. Uher R, Muthen B, Souery D, Mors O, Jaracz J, Placentino A, et al. Trajectories of change in depression severity during treatment with antidepressants. Psychol Med. 2010;40(8):1367-1377.
70. Connelly M, Keefe FJ, Affleck G, Lumley MA, Anderson T, Waters S. Effects of day-to-day affect regulation on the pain experience of patients with rheumatoid arthritis. Pain. 2007;131(1-2):162-170.

71. Peters EN, Hughes JR. The day-to-day process of stopping or reducing smoking: a prospective study of self-changers. Nic Tob Res. 2009;11(9):1083-1092.

72. Vowles KE, McCracken LM, Eccleston C. The processes of change in treatment for chronic pain: the contributions of pain, acceptance, and catastrophizing. Eur J Pain. 2007;11(7):779-787.

Corresponding author: Alan Fogel, $\mathrm{PhD}$, LMT, Department of Psychology, University of Utah, 380 S. 1530 E. Room 502, Salt Lake City, UT 841120251, USA

E-mail: fogel.alan@gmail.com 